\title{
Acidity and Characterization of 12-Tungstophosphoric Acid Supported on Silica-Alumina
}

\author{
Flávia C. G. de Mattos, Eduardo N. C. B. de Carvalho, Elon F. de Freitas, Mateus F. Paiva, \\ Grace F. Ghesti, Julio L. de Macedo,* Sílvia C. L. Dias and José A. Dias* \\ Laboratório de Catálise, Instituto de Química, Universidade de Brasília, Campus Darcy Ribeiro, \\ Asa Norte, CP 4478, 70904-970 Brasília-DF, Brazil
}

\begin{abstract}
This work deals with preparation and characterization of $\mathrm{H}_{3} \mathrm{PW}_{12} \mathrm{O}_{40}\left(\mathrm{H}_{3} \mathrm{PW}\right)$ supported on silica-alumina. Impregnation of $\mathrm{H}_{3} \mathrm{PW}(15,20,30$ and $40 \mathrm{wt} . \%)$ on commercial silica-alumina support in acidic aqueous solution is effective for preparing this catalyst keeping its Keggin structure, according to different methods of characterization. The catalysts were tested in a model reaction of acetic acid with ethanol and $30 \mathrm{wt} . \% \mathrm{H}_{3} \mathrm{PW} / \mathrm{SiO}_{2}-\mathrm{Al}_{2} \mathrm{O}_{3}$ had the highest activity under the conditions: catalyst calcination at $300{ }^{\circ} \mathrm{C}$, temperature of $100{ }^{\circ} \mathrm{C}$, acetic acid:ethanol molar ratio of 2:1 and catalyst:acetic acid mass ratio of $10 \mathrm{wt} . \%$. The reaction yield was 79 and $100 \%$ selectivity for ethyl acetate over three reutilizations, for reaction time of $2 \mathrm{~h}$. The calculated total acid site distribution was $0.299 \mathrm{mmol} \mathrm{g}^{-1}$ (97\% of the theoretical probed by pyridine), and most of these $\left(0.236 \mathrm{mmol} \mathrm{g}^{-1}\right)$ were Brønsted weak-medium strength (pyridine desorption between 300 and $\left.500{ }^{\circ} \mathrm{C}\right)$.
\end{abstract}

Keywords: supported heteropolyacid, 12-tungstophosphoric acid, silica-alumina, ethanol, esterification of acetic acid with ethanol

\section{Introduction}

An unique class of compounds known as polyoxometalates (POMs) is one of the many areas of inorganic chemistry that is developing rapidly. ${ }^{1}$ The synthesis of large clusters has been considered to be a notable advancement in this field due to their possible applications in nanoscience ${ }^{1-3}$ Because of the wide range of physical and chemical properties of these materials, they have been used in many technological fields as demonstrated by several reviews in the last decade. ${ }^{1,4-7}$

In particular, these materials have been utilized in catalytic applications. Keggin-type POMs have been used in both laboratory-scale reactions and industrial processes. ${ }^{8}$ A key catalytic compound is 12 -tungstophosphoric acid $\left(\mathrm{H}_{3} \mathrm{PW}_{12} \mathrm{O}_{40}, \mathrm{H}_{3} \mathrm{PW}\right)$, which has been heterogenized by anchoring it to a variety of supports (e.g., silica, alumina, zirconia, niobia) ${ }^{9-12}$ From POMs, $\mathrm{H}_{3} \mathrm{PW}$ is the strongest heteropolyacid (HPA), and its solid acidity can be finely controlled by heterogenization. ${ }^{13}$

A challenge in the technological application of supported HPA is to avoid leaching in polar solvents due

*e-mail: jdias@unb.br; julio@unb.br to their high solubility when it is used in batch reactions. ${ }^{5}$ Thus, a proper support that strongly interacts with the Keggin anion will enable the HPA specific surface to be enhanced, thereby increasing the accessibility of its acidic protons and keeping small nanocrystals on the surface. This idea has long been discussed in the literature, ${ }^{14}$ and despite some controversial results, it is generally accepted that the change of experimental conditions of preparation (e.g., solvent, temperature of calcination and method of impregnation) modifies the degree of interaction between the phases. ${ }^{8}$ For example, $\mathrm{H}_{3} \mathrm{PW}$ has been used to improve the activity of the chiral complex [Ru(BINAP)] (BINAP: 2,2'-bis(diphenylphosphino)-1,1'-binaphthyl) for the asymmetric hydrogenation of $\beta$-ketoesters. ${ }^{15}$ Whereas there is a strong interaction between the $\mathrm{H}_{3} \mathrm{PW}$ and the metal complex, ${ }^{14,15}$ an effective immobilization of the HPA on the alumina surface is required in order to keep the whole catalyst heterogeneous.

Silica-alumina is an important industrial material for various applications; for example, it is used in fluid catalytic cracking (FCC) catalysts and as support for other active phases. ${ }^{16}$ It is an amorphous mixed oxide network of interconnected silica and alumina tetrahedra that has both Brønsted and Lewis acid sites. The strength, distribution 
and number of those sites depend mostly on the amount of aluminum, which determines the catalytic and adsorptive properties of silica-alumina materials. ${ }^{16,17}$

Catalysts based on HPA supported on silica-alumina have not been widely explored in the literature mainly due to the supposed decomposition of the Keggin structure on the surfaces of aluminum oxide derivatives. ${ }^{18}$ However, it has been demonstrated that the decomposition of the Keggin anion can be controlled by utilizing the correct solvent and preparation method. ${ }^{10,19-21}$ In fact, $\mathrm{H}_{3} \mathrm{PMo}_{12} \mathrm{O}_{40}$ and $\mathrm{H}_{3} \mathrm{PW}_{12} \mathrm{O}_{40}$ supported on $\mathrm{SiO}_{2}-\mathrm{Al}_{2} \mathrm{O}_{3}$, prepared by different synthetic routes, performed satisfactorily in phenol tetrahydropyranylation ${ }^{22}$ and in the syntheses of azlactones. ${ }^{23} \mathrm{H}_{4} \mathrm{SiW}_{12} \mathrm{O}_{40}$ supported on silica-alumina with different $\mathrm{Si} / \mathrm{Al}$ ratios was tested in gas-phase glycerol dehydration, and showed good yields for acrolein. ${ }^{24}$ Moreover, other studies on supported HPA on various aluminosilicates (e.g., zeolites, clays, molecular sieves) have appeared in the literature, indicating that the Keggin anion can be stabilized on these surfaces. ${ }^{25-27}$ By stabilizing the Keggin anion, it is possible to produce nanocrystals of supported HPA, which are the major goal for most catalytic reactions.

This report details a wide-ranging study of $\mathrm{H}_{3} \mathrm{PW} / \mathrm{SiO}_{2}-\mathrm{Al}_{2} \mathrm{O}_{3}$ catalysts. A series of materials with various $\mathrm{H}_{3} \mathrm{PW}$ loadings was prepared, and their structural properties were characterized by Fourier transform infrared spectroscopy (FTIR), ${ }^{31} \mathrm{P}$ magic angle spinning nuclear magnetic resonance $\left({ }^{31} \mathrm{P}\right.$ MAS NMR), X-ray powder diffraction (XRD) and low-temperature $\mathrm{N}_{2}$ sorption. In addition, their reactivities were probed by studying: acidity by gaseous pyridine adsorption, leaching in ethanol and thermal stability under air flow by thermogravimetric and differential thermal (TG/DTA) analyses. Finally, these catalysts were employed in a model reaction of esterification of acetic acid with ethanol to produce ethyl acetate, which is an important reagent in industrial manufacturing, in order to correlate acidic strength, distribution and proposed reaction mechanism.

\section{Experimental}

\section{Synthesis of $\mathrm{H}_{3} \mathrm{PW}$ supported on silica-alumina}

$\mathrm{H}_{3} \mathrm{PW}$ used in the impregnations was obtained from Sigma. Silica-alumina (Aldrich, 12 wt. $\% \mathrm{Al}_{2} \mathrm{O}_{3}$ ) was pre-activated at $550{ }^{\circ} \mathrm{C}$ for $12 \mathrm{~h}$ to transform it from its ammoniacal form to its protonic form. The $\mathrm{x}$ wt.\% $\mathrm{H}_{3} \mathrm{PW} / \mathrm{SiO}_{2}-\mathrm{Al}_{2} \mathrm{O}_{3}$ materials, where $\mathrm{x}$ is the $\mathrm{H}_{3} \mathrm{PW}$ loading $\left(15,20,30\right.$ and 40 wt. $\%$; mass $\mathrm{H}_{3} \mathrm{PW} /\left(\right.$ mass $\mathrm{H}_{3} \mathrm{PW}+$ mass $\left.\mathrm{SiO}_{2}-\mathrm{Al}_{2} \mathrm{O}_{3}\right)$ ), were prepared by impregnation in an aqueous acid solution $\left(0.1 \mathrm{~mol} \mathrm{~L}^{-1} \mathrm{HCl}\right.$, Vetec). Specifically, calculated amounts of $\mathrm{H}_{3} \mathrm{PW}$ and $\mathrm{SiO}_{2}-\mathrm{Al}_{2} \mathrm{O}_{3}$ were placed in a $100 \mathrm{~mL}$ glass round-bottom flask with $10 \mathrm{~mL}$ of the acid solution per $\mathrm{g}$ of silica-alumina, and the suspension was maintained at $80^{\circ} \mathrm{C}$ under constant stirring until the solvent was completely dried. Then, the resulting materials were ground to fine particles and calcined in a muffle furnace (model EDG-3PS) under static air conditions at 200, 300 and $400{ }^{\circ} \mathrm{C}$ for $4 \mathrm{~h}$ (heating rate of $10{ }^{\circ} \mathrm{C} \mathrm{min}-1$ ). The catalysts were characterized by elemental analysis using energy dispersive X-ray fluorescence (EDX) spectrometer (Shimadzu EDX 720 with a rhodium X-ray tube). The X-ray fluorescence (XRF) spectra were collected under vacuum ( $<45 \mathrm{~Pa}$ ). The analyses were performed on powders placed inside the sample holder using a polypropylene film. The $\mathrm{H}_{3} \mathrm{PW}$ content was calculated based on $\mathrm{W}$ analysis determined by the QualiQuant method of fundamental standards. The nominal values of 15, 20, 30 and $40 \mathrm{wt} . \%$ were really $14.5 ; 20.3 ; 29.6$ and $39.8 \mathrm{wt} . \%$. As the actual values were close to the nominal ones, for simplicity the nominal values were used in this article.

\section{Characterization of $\mathrm{H}_{3} \mathrm{PW} / \mathrm{SiO}_{2}-\mathrm{Al}_{2} \mathrm{O}_{3}$}

The structures of these materials were characterized by FTIR, ${ }^{31} \mathrm{P}$ MAS NMR, XRD and nitrogen sorption. Their reactivities were probed by gas-phase pyridine adsorption, $\mathrm{H}_{3} \mathrm{PW}$ leaching in ethanol and thermal stability measurements under air.

The FTIR spectra of the samples were obtained using $1 \%$ of solid in dried $\mathrm{KBr}$ pellets in a Thermo Scientific Nicolet 6700 spectrophotometer (deuterated triglycine sulfate (DTGS) detector). The collected spectra used 256 scans with a $4 \mathrm{~cm}^{-1}$ resolution at $25^{\circ} \mathrm{C}$.

The XRD patterns were obtained on a Bruker D8 FOCUS using a copper tube $(\mathrm{Cu} \mathrm{K} \alpha, \lambda=1.5418 \AA$ at $40 \mathrm{kV}$ and $30 \mathrm{~mA}$ ). A $2 \theta$ step of $0.05^{\circ}$ and an integration time of $1 \mathrm{~s} \mathrm{step}^{-1}$ were used to scan $2 \theta$ values between of 5 and $60^{\circ}$.

The ${ }^{31} \mathrm{P}$ MAS NMR spectra were acquired in two apparatuses; $(i)$ for the samples calcined at $200^{\circ} \mathrm{C}$ : a Mercury Plus Varian of $7.05 \mathrm{~T}\left(300 \mathrm{MHz}\right.$ for $\left.{ }^{1} \mathrm{H}\right)$ spectrometer with a Varian $7 \mathrm{~mm} \mathrm{CP/MAS} \mathrm{(cross} \mathrm{polarization)} \mathrm{probe} \mathrm{(zirconia}$ rotor). The following conditions were set: frequency of 121.4 MHz, single-pulse excitation of $8.0 \mu$ s, acquisition time of $0.25 \mathrm{~ms}$, recycle delay of $10 \mathrm{~s}$, no ${ }^{1} \mathrm{H}$ decoupling, MAS rate of $5 \mathrm{kHz}$, and minimum of 512 acquisitions. Signals were referenced to $85 \%$ phosphoric acid ( $\delta 0 \mathrm{ppm}$ ); (ii) for the samples calcined at $300^{\circ} \mathrm{C}$ : a Bruker Avance III HD Ascend of $14.1 \mathrm{~T}\left(600 \mathrm{MHz}\right.$ for $\left.{ }^{1} \mathrm{H}\right)$ spectrometer with a $4 \mathrm{~mm}$ CP/MAS probe (zirconia rotor). The following conditions were set: a frequency of $243.1 \mathrm{MHz}$, single-pulse excitation 
(4.75 $\mu$ s duration), acquisition time of $0.1 \mathrm{~ms}$, recycle delay of $10 \mathrm{~s}$, no ${ }^{1} \mathrm{H}$ decoupling, MAS rate of $10 \mathrm{kHz}$ and minimum of 128 acquisitions. Signals were referenced to a secondary standard $\mathrm{NH}_{4} \mathrm{H}_{2} \mathrm{PO}_{4}(\delta 0.9 \mathrm{ppm})$ relative to $85 \%$ phosphoric acid $\left(\begin{array}{ll}\delta & 0 \mathrm{ppm}\end{array}\right)$. The spectra were adjusted to be referenced to $\mathrm{H}_{3} \mathrm{PO}_{4}$.

The textural properties (specific surface area $\left(\mathrm{S}_{\mathrm{BET}}\right)$ and pore volume) were calculated from nitrogen adsorption isotherms obtained at $-196{ }^{\circ} \mathrm{C}$ on a Micromeritics model ASAP $2020 \mathrm{C}$ instrument. The $\mathrm{S}_{\mathrm{BET}}$ value was calculated from the adsorption branch in the relative pressure range of $0.06-0.20$, whereas the total pore volume was obtained from the total amount of $\mathrm{N}_{2}$ adsorbed at pressures close to unity. The materials were calcined at $200{ }^{\circ} \mathrm{C}$ for $4 \mathrm{~h}$ and then degassed under vacuum at $120^{\circ} \mathrm{C}$ for $12 \mathrm{~h}$ before the measurements.

TG/DTG curves were obtained in a simultaneous TG-DSC equipment (TA Instruments, model SDT 2960), with heating rate of $10^{\circ} \mathrm{C} \mathrm{min}^{-1}$, from 25 up to $800^{\circ} \mathrm{C}$ under different atmospheres: (i) for stability study, it was used synthetic air $\left(80.0 \pm 0.5 \% \mathrm{~N}_{2}\right.$ and $\left.20.0 \pm 0.5 \% \mathrm{O}_{2}\right)$ flow of $110 \mathrm{~mL} \mathrm{~min}^{-1}$; and (ii) for determination of acidity, it was

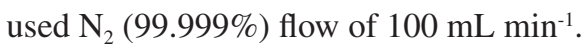

Gas-phase pyridine was adsorbed on the catalyst using a custom-made glass fixed bed reactor, using an in situ experiment. The supported samples were first dried at $200{ }^{\circ} \mathrm{C}$ for $4 \mathrm{~h}$ under vacuum in the reactor and then cooled to $100{ }^{\circ} \mathrm{C}$. Gaseous pyridine diluted in dry $\mathrm{N}_{2}$ was subsequently flowed over the samples for $1 \mathrm{~h}$. The reactor was then heated and maintained at $150{ }^{\circ} \mathrm{C}$ under vacuum for $1 \mathrm{~h}$ to remove all physically adsorbed pyridine. Finally, the samples with chemisorbed pyridine were analyzed immediately by TG/DTG and FTIR, in separated experiments.

Acidity, i.e., quantification of acid sites, was obtained by temperature programmed desorption (TPD) of pyridine using TG/DTG detection, by the difference between the curves of each catalyst before and after pyridine adsorption. Details of this calculation are in the Supplementary Information (SI) section and in the literature. ${ }^{28}$

The qualitative nature of acid sites was achieved by FTIR. Pellets with $10 \mathrm{wt} . \%$ of chemisorbed pyridine catalyst were prepared in a $\mathrm{N}_{2}$ glove box, placed in a holder, and taken straight to the FTIR spectrometer. The spectra were recorded at $25^{\circ} \mathrm{C}$.

Leaching tests of $\mathrm{H}_{3} \mathrm{PW}$ supported on silica-alumina (calcined at 200, 300 and $400{ }^{\circ} \mathrm{C}$ ) were performed with ethanol as solvent. The supported catalyst was evaluated by adding $50 \mathrm{~mL}$ of ethanol (Vetec, $99.8 \%$, previously dried over activated $3 \AA$ molecular sieves) to approximately $0.02 \mathrm{~g}$ of the solid at $25^{\circ} \mathrm{C}$. The resulting slurry was kept under magnetic stirring for $1 \mathrm{~h}$. Every $10 \mathrm{~min}$, the stirring was stopped to remove an aliquot using a $1.0 \mathrm{~mL}$ Hamilton gas-tight syringe with a membrane filter in the tip $(0.45 \mu \mathrm{m}$, $13 \mathrm{~mm}$ diameter). The $\mathrm{H}_{3} \mathrm{PW}$ concentration, corrected for the withdrawal volume, was measured by placing the sample in a $1 \mathrm{~cm}(0.5 \mathrm{~mL})$ quartz cuvette and using a Beckman DU 650 UV-Vis spectrophotometer at a wavelength of $263 \mathrm{~nm}$ (maximum of the $\left[\mathrm{PW}_{12} \mathrm{O}_{40}\right]^{3-}$ absorption band). The value was obtained using the following analytical curve for $\mathrm{H}_{3} \mathrm{PW}$ in ethanol (from $2 \times 10^{-6}$ up to $4 \times 10^{-5} \mathrm{~mol} \mathrm{~L}^{-1}$ ):

Absorbance $=4.2709 \times 10^{4}\left[\mathrm{H}_{3} \mathrm{PW}\right]+0.02542$,

$\mathrm{R}^{2}=0.9998\left(\mathrm{R}^{2}\right.$ is the correlation coefficient $)$

This method is able to detect 3-6 ppm of $\mathrm{H}_{3} \mathrm{PW}$, considering up to 3 times the lowest absorbance (A) reading in the curve (i.e., $\mathrm{A}=3 \times 0.02542=0.07626$ ).

Catalytic esterification using $\mathrm{H}_{3} \mathrm{PW} / \mathrm{SiO}_{2}-\mathrm{Al}_{2} \mathrm{O}_{3}$

The activity of the materials was evaluated in a model reaction of esterification of acetic acid (Vetec, 99.7\%) with ethanol (Vetec, 99.8\%). Acetic acid was used as supplied, and ethanol was placed in activated $3 \AA$ molecular sieves for at least $48 \mathrm{~h}$ before use. The reactions were performed in mini-reactors with capacities of 5 and $10 \mathrm{~mL}$ to which 1.00 and $2.00 \mathrm{~g}$ of acetic acid, respectively, were added. Ethanol was added to obtain molar ratio of 2:1, 1:1 or 1:2 (acetic acid:ethanol). Before the reaction, the catalyst was activated in a muffle furnace at $200{ }^{\circ} \mathrm{C}$ for $2 \mathrm{~h}$. The following parameters were optimized sequentially: (i) amount of $\mathrm{H}_{3} \mathrm{PW}(15,20,30$ and $40 \mathrm{wt} . \%)$ supported on silica-alumina; (ii) temperature $\left(80\right.$ and $\left.100{ }^{\circ} \mathrm{C}\right)$; (iii) acetic acid:ethanol molar ratio (2:1, 1:1 and 1:2); (iv) catalyst:acetic acid mass ratio $(2,5,10$ and $15 \mathrm{wt} . \%)$; and $(v)$ the reaction time (1, 2,4 and $6 \mathrm{~h}$ ). After each reaction, the system was allowed to cool to room temperature, the catalyst was separated by centrifugation, and the liquid phase was analyzed by gas chromatography (GC-17A Shimadzu with a flame ionization detector (FID) and polydimethylsiloxane column (CBPI PONA-M50-042)). The selectivity was $100 \%$ for ethyl acetate in all cases. The yield was obtained by the integration of the area peak of ethyl acetate and calculated with its standard analytical curve. Further experiments at reaction times of $15,30,45$ and 60 min were performed and allowed the calculation of the turnover frequency (TOF), according to the literature. ${ }^{28} \mathrm{~A}$ curve of yield of the product (mmol) versus time (s) was plotted for each catalyst in order to determine the initial activity, and each curve was fitted to a first-order polynomial function. The obtained function was differentiated, evaluated at $\mathrm{t}=0$ and 
the value divided by the total number of acid sites achieved by TPD of pyridine, i.e., $\mathrm{TOF}=$ mmol ethyl acetate $(\mathrm{EA})$ mmol sites ${ }^{-1} \mathrm{~s}^{-1}$.

\section{Results and Discussion}

\section{Structure and stability of the catalysts}

The stability of the Keggin structure on supports containing aluminum is a major concern and source of controversy in the literature. FTIR spectra of the $\mathrm{H}_{3} \mathrm{PW} / \mathrm{SiO}_{2}-\mathrm{Al}_{2} \mathrm{O}_{3}$ catalysts were obtained (Figure 1) to verify the presence of the Keggin structure by identifying the $\mathrm{H}_{3} \mathrm{PW}$ fingerprint bands. The silica-alumina support has absorption bands in the $1200-450 \mathrm{~cm}^{-1}$ region, which are assigned as follows: $1087 \mathrm{~cm}^{-1}, v_{\text {as }}(\mathrm{Si}-\mathrm{O}) ; 802 \mathrm{~cm}^{-1}$, $\mathrm{V}_{\text {as }}\left(\mathrm{Si}-\mathrm{O}^{-}\right) ; 578 \mathrm{~cm}^{-1}$, external $\delta\left(\mathrm{Si}-\mathrm{O}^{-}\right)$; and $462 \mathrm{~cm}^{-1}$, $\delta(\mathrm{Si}-\mathrm{O}-\mathrm{Si}) .{ }^{28}$ On the other hand, the main bands of $\mathrm{H}_{3} \mathrm{PW}$ are located at 1080, 983, 893 and $798 \mathrm{~cm}^{-1}$ and correspond to $\mathrm{P}-\mathrm{O}, \mathrm{W}=\mathrm{O}, \mathrm{W}-\mathrm{O}_{\text {corner }}-\mathrm{W}$ and $\mathrm{W}-\mathrm{O}_{\text {edge }}-\mathrm{W}$ asymmetric stretching vibrations, respectively. ${ }^{8}$ Because of the strong absorption of the support in the same region of the fingerprint bands of $\mathrm{H}_{3} \mathrm{PW}$, it is difficult to assign such bands due to overlaps, especially for lower $\mathrm{H}_{3} \mathrm{PW}$ loadings. However, it can be noted that the actual bands at 981 and $892 \mathrm{~cm}^{-1}$ became more visible with increasing $\mathrm{H}_{3} \mathrm{PW}$ loading. Even though quantitative analysis by FTIR using $\mathrm{KBr}$ pellets is not possible, such bands suggest the presence of the Keggin structure. Thus, it can be established that FTIR spectroscopy can partially prove the maintenance of the Keggin structure of $\mathrm{H}_{3} \mathrm{PW}$ supported on silica-alumina, as stated elsewhere. ${ }^{18}$

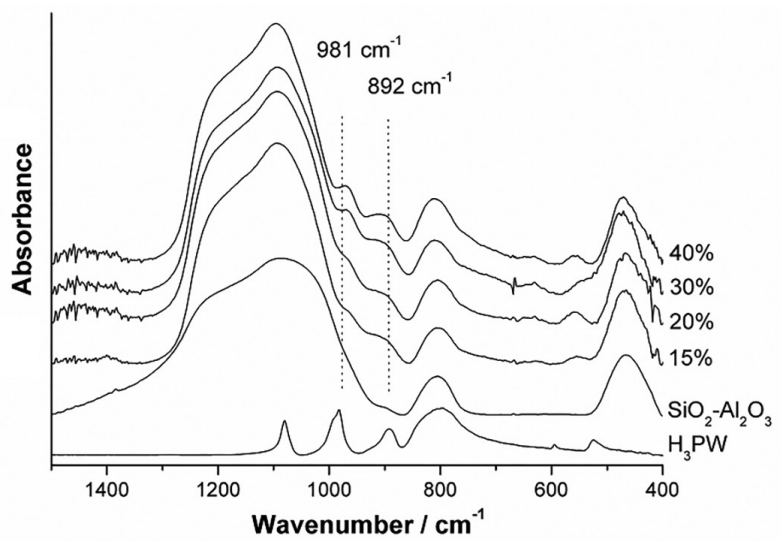

Figure 1. FTIR spectra ( $1 \% \mathrm{KBr}$ pellets) of $\mathrm{x}$ wt. $\% \mathrm{H}_{3} \mathrm{PW} / \mathrm{SiO}_{2}-\mathrm{Al}_{2} \mathrm{O}_{3}$ after calcination at $200^{\circ} \mathrm{C}$ for $4 \mathrm{~h}$.

XRD patterns of supported $\mathrm{H}_{3} \mathrm{PW}$ and the respective parent solids (i.e., silica-alumina and $\mathrm{H}_{3} \mathrm{PW}$ ) are compared in Figure 2. Silica-alumina is a known amorphous solid and presents only a large halo with maximum around $22-23^{\circ}(2 \theta)$. In contrast, $\mathrm{H}_{3} \mathrm{PW}$, treated at $300^{\circ}$ for $4 \mathrm{~h}$, showed a crystalline pattern compatible with the cubic structure (space group $\mathrm{Pn} 3 \mathrm{~m}$ ) with cell parameter $\mathrm{a}=12.16 \AA$, which is related to a hexahydrate crystalline phase. ${ }^{29}$ The most intense reflections for $\mathrm{H}_{3} \mathrm{PW}$ are $2 \theta$ at $10.4^{\circ}(110), 25.4^{\circ}(222)$ and $34.5^{\circ}(332)$. The crystallites of hydrated $\mathrm{H}_{3} \mathrm{PW}$ showed domain sizes greater than $50 \mathrm{~nm}$ by calculation using Scherrer's equation of that reflections. ${ }^{30}$

The XRD pattern of the supported $\mathrm{H}_{3} \mathrm{PW}$ is very similar to silica-alumina, except for a large reflection present at $7.9^{\circ}(2 \theta)(\mathrm{d}=1.1 \mathrm{~nm})$. The presence of this reflection has been interpreted in the literature as the X-ray scattering by non-ordered hydrated polyanions of $\mathrm{H}_{3} \mathrm{PW} .^{21}$ These polyanions are present at the surface either as isolated molecular moieties or as small clusters containing few Keggin units. The calculated crystalline domain sizes from broadening of that peak were about $2 \mathrm{~nm}$. A cluster of this size could contain about 4 Keggin units and may contain more hydrogen-bonded water molecules per unit than conventional bulk $\mathrm{H}_{3} \mathrm{PW} .{ }^{21}$ Therefore, the XRD data presented an indication for the existence of $\mathrm{H}_{3} \mathrm{PW}$ adsorbed on silica-alumina in the form of hydrated surface molecular species or of small nanoclusters containing few Keggin units. Nonetheless, definitive information about their molecular structure could not be extended. To clarify the structural integrity of the Keggin anion after the adsorption on the support, it was conducted additional ${ }^{31}$ P MAS NMR spectroscopy at different calcination temperatures.

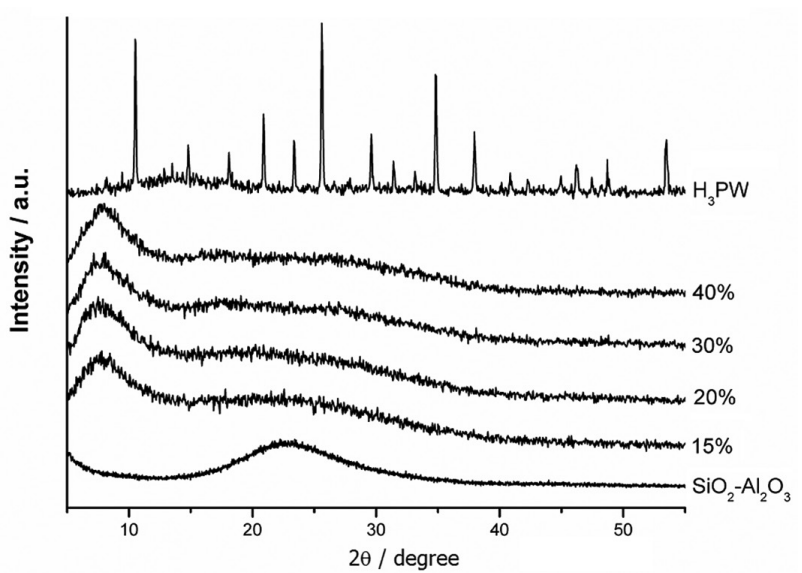

Figure 2. XRD patterns of $x$ wt. $\% \mathrm{H}_{3} \mathrm{PW} / \mathrm{SiO}_{2}-\mathrm{Al}_{2} \mathrm{O}_{3}$ after calcination at $200{ }^{\circ} \mathrm{C}$ for $4 \mathrm{~h}$.

${ }^{31} \mathrm{P}$ MAS NMR spectroscopy can establish the presence of the Keggin structure for supported $\mathrm{H}_{3} \mathrm{PW}$ more definitively than FTIR and XRD. Figure 3a shows the spectra of the supported $\mathrm{x}$ wt. $\% \mathrm{H}_{3} \mathrm{PW}$ calcined at $200^{\circ} \mathrm{C}$, as well as the hexahydrate $(-15.2 \mathrm{ppm})$ and the anhydrous $\mathrm{H}_{3} \mathrm{PW}(-11.1 \mathrm{ppm})$. For that, at 15 wt. $\% \mathrm{H}_{3} \mathrm{PW}$ loading, 
there are two signals: one at $-12.9 \mathrm{ppm}$ and another at $-11.2 \mathrm{ppm}$. For higher loadings (20, 30 and $40 \mathrm{wt} . \%)$, there is only a single resonance at $-12.9 \mathrm{ppm}$. These results showed that the signal of the Keggin structure was displaced from the original hexahydrate condition to a lower degree of hydration, as a function of calcination. This is sustained by similar results obtained for $\mathrm{H}_{3} \mathrm{PW}$ supported on alumina and niobia. ${ }^{10,12}$ Formation of lacunary species $\left(\left[\mathrm{PW}_{11} \mathrm{O}_{39}\right]^{7-}\right)$ is disregarded because no characteristic signal at $-10.4 \mathrm{ppm}$ is present. ${ }^{31}$ Thus, this corroborates to an interaction between the Keggin structure and the support, which gave rise to the shift in the main hydrate $\mathrm{H}_{3} \mathrm{PW}$ Keggin signal and an additional signal. According to literature, ${ }^{32-34}$ analyses by FTIR, Raman, X-ray photoelectron spectroscopy (XPS), ${ }^{1} \mathrm{H}$ and ${ }^{31} \mathrm{P}$ MAS NMR and extended X-ray absorption fine structure (EXAFS) revealed the formation of species like $\left[\left(\equiv \mathrm{SiOH}_{2}\right)_{3} \mathrm{PW}_{12} \mathrm{O}_{40}\right],\left[\left(\equiv \mathrm{SiOH}_{2}\right)_{x} \mathrm{H}_{3-\mathrm{x}} \mathrm{PW}_{12} \mathrm{O}_{40}\right]$ or $\left[(\equiv \mathrm{Si})_{\mathrm{x}}{ }^{+} \mathrm{H}_{3-\mathrm{x}} \mathrm{PW}_{12} \mathrm{O}_{40}{ }^{-}+\mathrm{H}_{2} \mathrm{O}\right]$ on silica surface, remaining stable up to $300{ }^{\circ} \mathrm{C}$. Depending on the thermal treatment, the highly acidic protons reacted with a protonated silanol, leading to the evolution of water and the formation of $\mathrm{Si}-\mathrm{O}-\mathrm{W}$ bonds. ${ }^{33}$

An additional evidence for that arose from the spectra of the supported samples calcined at $300{ }^{\circ} \mathrm{C}$ (Figure $3 b$ ). The spectra of supported $\mathrm{H}_{3} \mathrm{PW}$ showed similar shifts to $-13.2 \mathrm{ppm}$, as well as other broad signals at -11.5 and $-11.0 \mathrm{ppm}$. As it is known in the literature, ${ }^{35}$ the higher calcination temperature, the lower hydration degree of the Keggin structure, limited by stability temperature for the Keggin anion. Thus, anhydrous $\mathrm{H}_{3} \mathrm{PW}$ exhibited a single signal around -10 to -11 ppm. ${ }^{8,12}$ It is worth to note the differences on the characteristic signals of the anhydrous, hydrated and supported $\mathrm{H}_{3} \mathrm{PW} /$ silica-alumina. Pure hydrated $\mathrm{H}_{3} \mathrm{PW}$ shows a single signal (ca. -14 up to $-16 \mathrm{ppm}$, according to many reports in the literature) and the full width at half maximum (FWHM) is about $45 \mathrm{~Hz}$; anhydrous $\mathrm{H}_{3} \mathrm{PW}$ has a single signal (ca. -10 to $-11 \mathrm{ppm}$ ) with linewidth around $95 \mathrm{~Hz}$; supported on silica-alumina, the signals of $\mathrm{H}_{3} \mathrm{PW}$ were growing broader $(15,20,30$ and 40 wt. $\% \mathrm{H}_{3} \mathrm{PW} / \mathrm{SiO}_{2}-\mathrm{Al}_{2} \mathrm{O}_{3}$ calcined at $200{ }^{\circ} \mathrm{C}$, FWHMs were $50,90,102$ and $111 \mathrm{~Hz}$ for the signal at $-12.9 \mathrm{ppm}$, respectively). The same trend in FWHM was observed when the materials were calcined at $300{ }^{\circ} \mathrm{C}$. In principle, the line broadening observed in the supported $\mathrm{H}_{3} \mathrm{PW}$ on silica-alumina depends on the dipolar interaction between ${ }^{31} \mathrm{P}$ and ${ }^{27} \mathrm{Al}$ nuclei, which is not averaged to zero by magic angle spinning of a quadrupolar nucleus as Al. Nonetheless, it is stated that this dipolar interaction is not the only responsible for that broadening based on the results observed for supported 12-molybdophosphoric acid, ${ }^{18}$ which was much broader than those of supported $\mathrm{H}_{3} \mathrm{PW}$.
Thus, the broadening of the ${ }^{31} \mathrm{P}$ NMR signals as a function of calcination temperature may be taken as an indication of an interaction of $\mathrm{H}_{3} \mathrm{PW}$ and silica-alumina support. Moreover, ${ }^{31} \mathrm{P}$ MAS NMR spectrum of a mechanical mixture of $\mathrm{H}_{3} \mathrm{PW}$ and silica-alumina (e.g., $20 \mathrm{wt} . \% \mathrm{H}_{3} \mathrm{PW}$ ) gave rise to a similar spectrum of pure $\mathrm{H}_{3} \mathrm{PW}$ (single signal at $-15.2 \mathrm{ppm}$ and FWHM of $46 \mathrm{~Hz}$ ), as already observed for mechanical mixtures with silica. ${ }^{9}$

The nature of interaction between $\mathrm{H}_{3} \mathrm{PW}$ and silicaalumina can be inferred based on the knowledge of silica-alumina surface. The characteristics of acid sites on amorphous silica-alumina have been debated for a long time in the literature. ${ }^{17,36-38}$ However, different reports using diffuse reflectance Fourier transformed infrared spectroscopy (DRIFTS), density functional theory (DFT) and their combination have clarified it. ${ }^{17}$ It has been proposed that silica-alumina surface is formed by isolated silanols and/or hydrogen-bonded bridge silanols..$^{17,39}$ The highest frequencies of $\mathrm{OH}$ vibrations are found for $\mathrm{Si}-\mathrm{OH}$ groups (isolated silanols) and $\mathrm{O}-\mathrm{Si}-\mathrm{OH}-\mathrm{Al}$ groups (called aluminic pseudo-bridging silanols). ${ }^{17}$ Thus, it may be suggested that the interaction of $\mathrm{H}_{3} \mathrm{PW}$ Keggin structure can take place preferentially at these sites, since most of the metal oxides interact to $\mathrm{O}-\mathrm{H}$ surface sites of different supports. ${ }^{39,40}$

Nitrogen physisorption isotherm obtained for $\mathrm{SiO}_{2}-\mathrm{Al}_{2} \mathrm{O}_{3}$ was analyzed by plotting the $t$-curve, i.e.,
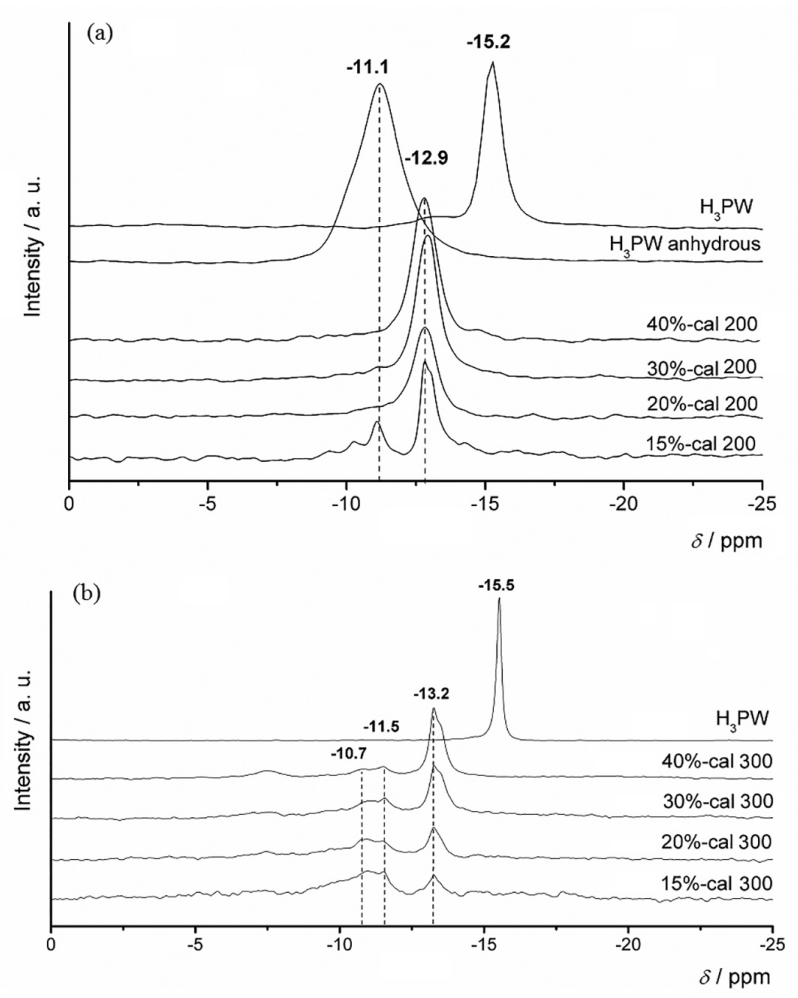

Figure 3. ${ }^{31} \mathrm{P}$ MAS NMR spectra of $\mathrm{x}$ wt. $\% \mathrm{H}_{3} \mathrm{PW} / \mathrm{SiO}_{2}-\mathrm{Al}_{2} \mathrm{O}_{3}$ referenced to $85 \% \mathrm{H}_{3} \mathrm{PO}_{4}$ : (a) samples calcined at $200{ }^{\circ} \mathrm{C}$ for $4 \mathrm{~h}$ and obtained at $7.05 \mathrm{~T}$, and (b) samples calcined at $300^{\circ} \mathrm{C}$ for $4 \mathrm{~h}$ and obtained at $14.1 \mathrm{~T}$. 
amount of $\mathrm{N}_{2}$ adsorbed versus thickness ( $\left.\mathrm{t}\right){ }^{41}$ The linear fit from the latter showed a straight line passing through the origin, which indicates a multilayer adsorption of $\mathrm{N}_{2}$ on the solid surface (Figure S1, in the SI section). The absence of low or high pressure deviations in the $t$-curve evidenced that $\mathrm{SiO}_{2}-\mathrm{Al}_{2} \mathrm{O}_{3}$ porosity is not related to the presence of micropores or cylindrical mesopores, respectively. ${ }^{41}$ Indeed, adsorption/desorption isotherms showed a type IV curve and type $\mathrm{H} 2$ hysteresis, which indicated capillary condensation in macropores or inkbottle-type mesopores.

The main textural properties of the prepared materials also revealed how $\mathrm{H}_{3} \mathrm{PW}$ and $\mathrm{SiO}_{2}-\mathrm{Al}_{2} \mathrm{O}_{3}$ interacted with each other. The nature of the support and the conditions used in the catalyst synthesis are important parameters for improving the stability of $\mathrm{H}_{3} \mathrm{PW}$ supported materials. ${ }^{9-12,42}$ The commercial silica-alumina showed $489 \mathrm{~m}^{2} \mathrm{~g}^{-1}\left(\mathrm{~S}_{\mathrm{BET}}\right)$ and $0.69 \mathrm{~cm}^{3} \mathrm{~g}^{-1}$ of pore volume $\left(\mathrm{P}_{\mathrm{v}}\right)$. Isotherms and $t$-curves of the supported $\mathrm{H}_{3} \mathrm{PW}$ are presented in Figures $\mathrm{S} 2$ to $\mathrm{S} 5$ (in the SI section). $\mathrm{S}_{\mathrm{BET}}$ and $\mathrm{P}_{\mathrm{v}}$ of the $\mathrm{H}_{3} \mathrm{PW} / \mathrm{SiO}_{2}-\mathrm{Al}_{2} \mathrm{O}_{3}$ materials decreased linearly $\left(\mathrm{R}^{2}=0.992\right.$ and 0.994 , respectively) as the $\mathrm{H}_{3} \mathrm{PW}$ loading increased from 15 to $40 \mathrm{wt} . \%$ (Table 1). This behavior was related to the impregnation of $\mathrm{H}_{3} \mathrm{PW}$ on $\mathrm{SiO}_{2}-\mathrm{Al}_{2} \mathrm{O}_{3}$ surface and porous system. The actual decrease of $\mathrm{S}_{\mathrm{BET}}$ with $\mathrm{H}_{3} \mathrm{PW}$ loading was also analyzed by considering the amount of $\mathrm{SiO}_{2}-\mathrm{Al}_{2} \mathrm{O}_{3}$ in the materials. For example, the sample containing $40 \%$ of $\mathrm{H}_{3} \mathrm{PW}$ has only $60 \%$ of $\mathrm{SiO}_{2}-\mathrm{Al}_{2} \mathrm{O}_{3}$, which would be accountable for a surface area of $293 \mathrm{~m}^{2} \mathrm{~g}^{-1}$ (normalized based on the $\mathrm{S}_{\mathrm{BET}}$ for pure $\mathrm{SiO}_{2}-\mathrm{Al}_{2} \mathrm{O}_{3}$ ). The actual $\mathrm{S}_{\mathrm{BET}}$ value obtained for the sample with $40 \%$ of $\mathrm{H}_{3} \mathrm{PW}$ was $240 \mathrm{~m}^{2} \mathrm{~g}^{-1}$, resulting in a decrease of only $53 \mathrm{~m}^{2} \mathrm{~g}^{-1}$. Table 1 shows the normalized $\left(\mathrm{S}_{\mathrm{N}}\right)$ and decreased $\left(\mathrm{S}_{\mathrm{D}}\right)$ calculated specific surface values for all the samples, indicating that an approximated constant decrease of surface area was reached around 30\% of impregnation. These results and the theoretical coverage on the support indicated that an increase of $\mathrm{H}_{3} \mathrm{PW}$ above $30 \%$ ( 0.20 coverage) may result in some $\mathrm{H}_{3} \mathrm{PW}$ agglomeration, see Table 1 .

The stability of $\mathrm{H}_{3} \mathrm{PW} / \mathrm{SiO}_{2}-\mathrm{Al}_{2} \mathrm{O}_{3}$ was evaluated by TG/DTG curves under air flow and pure $\mathrm{H}_{3} \mathrm{PW}$ and curves for silica-alumina (Figure S6a-b, in the SI section) were provided for comparison. The TG/DTG curves for $\mathrm{H}_{3} \mathrm{PW}$ show three thermal events. ${ }^{40}$ The first mass loss, between 25 and $100{ }^{\circ} \mathrm{C}$, was due to release of physically adsorbed water and some of the hydrating water molecules, forming $\mathrm{H}_{3} \mathrm{PW} \cdot 6 \mathrm{H}_{2} \mathrm{O}$. The temperature range and maximum might vary based on the initial amount of water in the material. ${ }^{40}$ The second mass loss occurred between 120 and $240{ }^{\circ} \mathrm{C}$ (maximum at approximately $170{ }^{\circ} \mathrm{C}$ ) and corresponded to the formation of the anhydrous catalyst. Finally, the third step occurred over a wide temperature range (approximately $380-600{ }^{\circ} \mathrm{C}$ ), which is related to the decomposition of the Keggin anion by formation of the anhydride $\left(\mathrm{PW}_{12} \mathrm{O}_{38.5}\right)$ followed by total transformation in the oxides $\left(\mathrm{P}_{2} \mathrm{O}_{5}\right.$ and $\mathrm{WO}_{3}$ ). ${ }^{40}$ The location of the maximum (usually between 450 and $470{ }^{\circ} \mathrm{C}$ ) cannot be precisely determined because of the wide peak width. On the other hand, supported $\mathrm{H}_{3} \mathrm{PW} / \mathrm{SiO}_{2}-\mathrm{Al}_{2} \mathrm{O}_{3}$ presented similar curves (Figure S6c-f, in the SI section), but showed basically two thermal events. The first mass loss occurred between $50-250{ }^{\circ} \mathrm{C}$ (maximum at about $100{ }^{\circ} \mathrm{C}$ ), which is associated to the release of physically adsorbed water and hydrating water molecules attached to the protons in the secondary structure of HPA. A second notable mass loss took place between $400-600{ }^{\circ} \mathrm{C}$ (maximum at $510{ }^{\circ} \mathrm{C}$ ), which can be assigned to fragmentation of Keggin anion followed by the total decomposition of $\mathrm{H}_{3} \mathrm{PW}$ at about $600{ }^{\circ} \mathrm{C}$. It can be noted that the supported HPA may be considered slightly more stable than pure $\mathrm{H}_{3} \mathrm{PW}$, and probably silica-alumina underwent some dehydroxylation, which also contributed to the mass loss processes.

A last point should be addressed to the stability of $\mathrm{H}_{3} \mathrm{PW}$. The utilized commercial silica-alumina had a Si/Al ratio of 6.2. Structural studies confirmed that the Keggin anion was not destroyed, consistent to our previous report ${ }^{10}$ and others ${ }^{25-27}$ about the stability of HPAs in the presence of aluminum containing supports. However, the surface interactions and acidity could still be finely tuned to optimize the catalyst for efficient performance in a given reaction.

Table 1. Textural properties of $\mathrm{x}$ wt. $\% \mathrm{H}_{3} \mathrm{PW} / \mathrm{SiO}_{2}-\mathrm{Al}_{2} \mathrm{O}_{3}$

\begin{tabular}{|c|c|c|c|c|c|}
\hline Catalyst / wt. $\% \mathrm{H}_{3} \mathrm{PW}$ & $\mathrm{S}_{\mathrm{BET}^{a}}{ }^{\mathrm{a}} /\left(\mathrm{m}^{2} \mathrm{~g}^{-1}\right)$ & $\mathrm{S}_{\mathrm{N}}{ }^{\mathrm{b}} /\left(\mathrm{m}^{2} \mathrm{~g}^{-1}\right)$ & $\mathrm{S}_{\mathrm{D}}^{\mathrm{c}} /\left(\mathrm{m}^{2} \mathrm{~g}^{-1}\right)$ & $\mathrm{P}_{\mathrm{v}}^{\mathrm{d}} /\left(\mathrm{cm}^{3} \mathrm{~g}^{-1}\right)$ & Coverage $^{\mathrm{e}}$ \\
\hline 0 & 489 & 489 & 0 & 0.69 & 0 \\
\hline 15 & 402 & 416 & 14 & 0.44 & 0.09 \\
\hline 20 & 372 & 391 & 19 & 0.41 & 0.12 \\
\hline 30 & 292 & 342 & 50 & 0.35 & 0.21 \\
\hline 40 & 240 & 293 & 53 & 0.27 & 0.32 \\
\hline
\end{tabular}

a Specific surface area calculated by BET method (error $\left.\pm 2 \mathrm{~m}^{2} \mathrm{~g}^{-1}\right)$; ${ }^{\mathrm{b}}$ specific surface area normalized to $1 \mathrm{~g}$ of pure silica-alumina; 'actual decrease of $\mathrm{S}_{\mathrm{BET}}$; d pore volume obtained from the amount of $\mathrm{N}_{2}$ adsorbed at pressures close to unity; ${ }^{41,43}{ }^{\mathrm{e}} \mathrm{H}_{3} \mathrm{PW}$ coverage calculated according to equation described elsewhere. ${ }^{11}$ 


\section{Catalyst: reactivity, acidity and recycling}

Short-chain esters are widely used as solvents and in the production of chemicals for chemical and pharmaceutical industries. ${ }^{44}$ Alkyl ester production is most frequently achieved by the esterification of carboxylic acids with alcohols using a homogeneous Brønsted acid catalyst such as sulfuric acid. However, when a liquid mineral acid is used as the catalyst, an additional neutralization step is usually required, contributing to catalyst degradation and chemical waste generation. ${ }^{45}$ Currently, the development of heterogeneous catalysts is important for creating more environmentally friendly processes. Therefore, the heterogeneous catalytic esterification of acetic acid with ethanol was optimized using the $\mathrm{H}_{3} \mathrm{PW} / \mathrm{SiO}_{2}-\mathrm{Al}_{2} \mathrm{O}_{3}$ materials. This can be an alternative route to traditional Fischer esterification either in batch or even in fixed bed reactors.

A preliminary study was performed to check the best calcination temperature of the catalysts, and thus the highest possible activity of the catalysts. $30 \mathrm{wt} \% \mathrm{H}_{3} \mathrm{PW} / \mathrm{SiO}_{2}-\mathrm{Al}_{2} \mathrm{O}_{3}$ was calcined at 200,300 and $400{ }^{\circ} \mathrm{C}$, and subjected to the leaching test with ethanol. The results indicated that no leaching was detected under the UV-Vis method for the tested at temperatures of 300 and $400{ }^{\circ} \mathrm{C}$ of calcination. Thus, a calcination treatment at $300{ }^{\circ} \mathrm{C}$ was adopted since it is known that this temperature is efficient to keep acidity and increase the interaction of $\mathrm{H}_{3} \mathrm{PW}$ on the support. ${ }^{9-12}$

Next, the optimal $\mathrm{H}_{3} \mathrm{PW}$ loading was determined using the following reaction conditions: a temperature of $100{ }^{\circ} \mathrm{C}$, reaction time of $4 \mathrm{~h}$, acetic acid:ethanol molar ratio of $2: 1$ and catalyst:acetic acid mass ratio of $10 \mathrm{wt} \%$. Figure 4 shows the results, which indicate that $30 \mathrm{wt} . \% \mathrm{H}_{3} \mathrm{PW} / \mathrm{SiO}_{2}-\mathrm{Al}_{2} \mathrm{O}_{3}$ was the most active catalyst (approximately $78.3 \%$ ethyl acetate yield with $100 \%$ selectivity). In addition, the reaction with 30 wt. $\% \mathrm{H}_{3} \mathrm{PW} / \mathrm{SiO}_{2}-\mathrm{Al}_{2} \mathrm{O}_{3}$ was repeated under the same conditions, but at $80^{\circ} \mathrm{C}$. The yield decreased to approximately $54.8 \%$; thus, $100{ }^{\circ} \mathrm{C}$ was determined to be the optimal temperature. It should be noted that using pure silica-alumina, yield was about $42 \%$ under the same experimental conditions (first point in Figure 4).

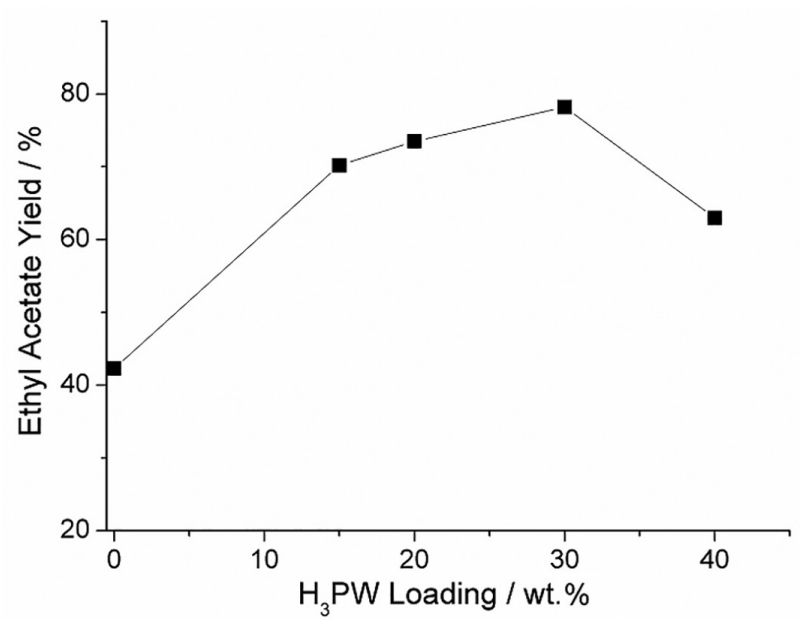

Figure 4. Effect of the $\mathrm{H}_{3} \mathrm{PW}$ loading (x wt.\%) on the esterification of acetic acid with ethanol catalyzed by $x$ wt. $\% \mathrm{H}_{3} \mathrm{PW} / \mathrm{SiO}_{2}-\mathrm{Al}_{2} \mathrm{O}_{3}$. Conditions: $100{ }^{\circ} \mathrm{C}, 4 \mathrm{~h}, 2: 1$ acetic acid:ethanol molar ratio, $10 \mathrm{wt} \%$ catalyst:acetic acid mass ratio.

Nevertheless, to compare the intrinsic activity of each catalyst, the reaction was measured at a low conversion range, i.e., below $1 \mathrm{~h}$ reaction time. The curves of ethyl acetate yield versus time are shown in Figure S7 (in the SI section). The yield is practically linear with increasing $\mathrm{H}_{3} \mathrm{PW}$ loading, and no mass or diffusion effect could be noted. Thus, the calculated TOF was based on the curve fitting of the plot to a first-order polynomial function. This function was differentiated, evaluated at $t=0$ and divided by the number of total acid sites obtained by TPD of pyridine for each catalyst (Table 2). It can be confirmed that the most active catalyst is the $30 \mathrm{wt} . \% \mathrm{H}_{3} \mathrm{PW} / \mathrm{SiO}_{2}-\mathrm{Al}_{2} \mathrm{O}_{3}$.

The acetic acid:ethanol molar ratio $(2: 1 ; 1: 1$ and $1: 2)$ in the esterification reaction was varied to determine its effect on the catalyst activity. The catalytic runs were performed at $100{ }^{\circ} \mathrm{C}$ for $4 \mathrm{~h}$ using $10 \mathrm{wt} . \%$ of

Table 2. Acidity and catalytic properties of $\mathrm{H}_{3} \mathrm{PW}$ supported on silica-alumina

\begin{tabular}{lcccc}
\hline Catalyst / wt. $\% \mathrm{H}_{3} \mathrm{PW}$ & $\mathrm{n} \mathrm{H}_{3} \mathrm{PW}^{\mathrm{a}} /\left(\mathrm{mmol} \mathrm{g}^{-1}\right)$ & $\mathrm{TG} \mathrm{probed}^{\mathrm{b}} /\left(\mathrm{mmol} \mathrm{g}^{-1}\right)$ & Total H$_{3} \mathrm{PW}^{\mathrm{c}} / \%$ & $\mathrm{TOF}^{\mathrm{d}}$ \\
\hline 0 & 0 & 0.240 & 0 & - \\
15 & 0.155 & 0.271 & 174.8 & 0.040 \\
20 & 0.206 & 0.287 & 139.3 & 0.042 \\
30 & 0.309 & 0.299 & 96.7 & 0.054 \\
40 & 0.412 & 0.373 & 90.5 & 0.035 \\
100 & 1.037 & 0.959 & 92.5 & - \\
\hline
\end{tabular}

a Theoretical amount of total protons on $\mathrm{H}_{3} \mathrm{PW}$ supported; ${ }^{\mathrm{b}}$ acidity obtained by desorption of pyridine by $\mathrm{TG}$ analysis $\left(300-600^{\circ} \mathrm{C}\right)$; ${ }^{\mathrm{c}}$ theoretical amount of total protons of $\mathrm{H}_{3} \mathrm{PW}$ neutralized by pyridine, assuming none at silica-alumina; ${ }^{\mathrm{d}} \mathrm{TOF}$ (turnover frequency) of ethanol and acetic acid reaction (mol ethyl acetate (EA) $\mathrm{mol}^{-1}$ acid sites s${ }^{-1}$ ) were obtained according to data of Figure S7 (in the SI section). The mols of acid sites were those probed experimentally by TG. 
30 wt. $\% \mathrm{H}_{3} \mathrm{PW} / \mathrm{SiO}_{2}-\mathrm{Al}_{2} \mathrm{O}_{3}$. Figure 5 shows that the highest ethyl acetate yield (78.3\%) was achieved when the molar ratio was $2: 1$. The yield decreased to 63.4 and $56.0 \%$ when the molar ratio was $1: 2$ and $1: 1$, respectively. The esterification is an equilibrium reaction, and the products are formed when one of the reactants is used in excess or when one of the products is removed from the reactor. The increase in the ethyl acetate yield when acetic acid was in excess could be attributed to the contribution of acetic acid to the self-catalyzed reaction. However, the kinetics of self-catalyzed esterification reactions is usually negligible, and a catalyst must be used to improve the kinetics and yield. ${ }^{46} \mathrm{~A}$ blank experiment without any catalyst showed only $24 \%$ yield (first point in Figure 6). It has been suggested that an excess of alcohol in the esterification reduces the ester production by blocking the catalyst active sites. ${ }^{47,48}$ The results in this report are also in agreement with a recent catalytic esterification study using $\mathrm{H}_{3} \mathrm{PW}-\mathrm{TaO}_{5}$ nanocomposite, which obtained the highest conversion using a 2:1 acetic acid to ethanol molar ratio. ${ }^{49}$ Also, a study of this reaction with the same $2: 1$ molar ratio, using $30 \mathrm{wt} . \% \mathrm{H}_{3} \mathrm{PW} /$ montmorillonite $\mathrm{K} 10$ under approximately similar experimental conditions of our report, yielded $90 \%$ ethyl acetate, but at $8 \mathrm{~h}$ reaction..$^{50}$

The behavior of the higher yield with excess of acetic acid was consistent to other mechanism studies in the literature. ${ }^{51}$ It has been proposed a single-site mechanism (Eley-Riedel) in which the adsorbed carboxylic acid reacts with the alcohol (methanol or ethanol) in both gas/liquid-phase, describing the kinetics very satisfactorily. ${ }^{51}$ Briefly, the $\mathrm{H}_{3} \mathrm{PW} / \mathrm{SiO}_{2}-\mathrm{Al}_{2} \mathrm{O}_{3}$ catalyst furnished a proton to react with the acyl group of acetic acid, allowing it to be more electrophylic, followed by the substitution of an $\mathrm{O}-\mathrm{H}$ group by an O-Et group from ethanol (nucleophile)

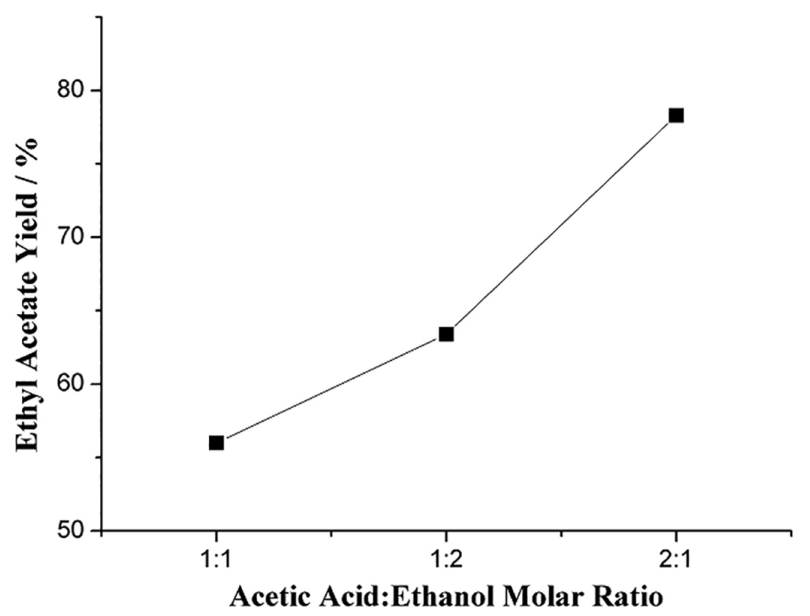

Figure 5. Effect of the acetic acid:ethanol molar ratio on the esterification reaction catalyzed by $30 \mathrm{wt} . \% \mathrm{H}_{3} \mathrm{PW} / \mathrm{SiO}_{2}-\mathrm{Al}_{2} \mathrm{O}_{3}$. Conditions: $100{ }^{\circ} \mathrm{C}$, 4 h, 10 wt.\% catalyst:acetic acid mass ratio.

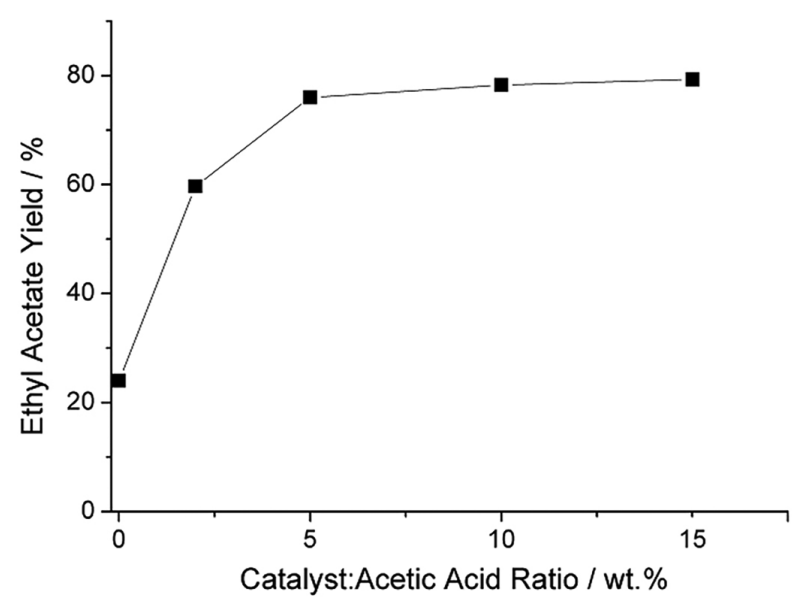

Figure 6. Effect of the catalyst mass on the esterification of acetic acid with ethanol catalyzed by $30 \mathrm{wt} . \% \mathrm{H}_{3} \mathrm{PW} / \mathrm{SiO}_{2}-\mathrm{Al}_{2} \mathrm{O}_{3}$. Conditions: $100^{\circ} \mathrm{C}$, $4 \mathrm{~h}, 2: 1$ acetic acid:ethanol molar ratio.

and the release of a water molecule after the formation of a tetra-coordinated intermediate.

The effect of the amount of catalyst was subsequently tested. Figure 6 presents the influence of the catalyst mass on the ethyl acetate production at $100{ }^{\circ} \mathrm{C}$ over $4 \mathrm{~h}$ using an acetic acid:ethanol molar ratio of 2:1. As the amount of catalyst was increased up to $10 \mathrm{wt}$.\% (based on the acetic acid mass), the ethyl acetate yield considerably increased, 59.7, $76.0,78.3$ and $79.4 \%$, for $2.5,5,10$ and $15 \mathrm{wt} . \%$ of catalyst, respectively. Repeating the experiment at lower times $(1 \mathrm{~h}$ reaction), it was obtained $69.2,73.3$ and $74.4 \%$ for 5,10 and $15 \%$ of catalyst, respectively. Figure 6 could be divided in two linear sections: up to 5\% and from 5 to $15 \%$. It is clear that above $5 \%$, there is only a slight linear increase of yield with the amount of the catalyst. Actually, above a mass ratio of $5 \mathrm{wt} . \%$, the yield was nearly constant. Nonetheless, based on the whole curve (2.5 to $15 \%$ ), the increased yield is not linear with the amount of catalyst. These results indicate that the esterification of acetic acid with ethanol depends on the catalyst amount, i.e., the number of acid sites, to some extent, below $5 \mathrm{wt} . \%$. According to the literature, ${ }^{47}$ the increase in the ethyl acetate yield with the number of acid sites suggests that the reaction rate depends on the catalyst concentration. The non-linear increase in the product yield between 2.5 to $15 \mathrm{wt}$. \% of the catalyst might indicate masslimiting diffusion. As in the range of 5 to $15 \mathrm{wt} . \%$ catalyst, the yield was approximately constant, $10 \mathrm{wt} . \%$ was chosen to be the optimal amount of catalyst. As presented, the study of yield versus time (Figure S7, in the SI section), below than $1 \mathrm{~h}$, with $10 \mathrm{wt} . \%$ catalyst showed a linear fit for the different $x$ wt. $\% \mathrm{H}_{3} \mathrm{PW} / \mathrm{SiO}_{2}-\mathrm{Al}_{2} \mathrm{O}_{3}$ catalysts, confirming no mass diffusion effects under these experimental conditions.

Finally, the ethyl acetate yield was measured as a function of time under the optimized conditions. Figure 7 
shows that the product formation increased between 1 and $2 \mathrm{~h}$ of reaction time (70 to $79 \%$ ). The yield was approximately constant at longer reaction times of 4 and $6 \mathrm{~h}(80 \pm 3 \%)$. These results demonstrate that most of the catalysis occurred within approximately $1 \mathrm{~h}$, because control experiments performed under the same conditions (i.e., $1 \mathrm{~h}$ reaction) without the catalyst or with only silicaalumina resulted in product yields of approximately 19 and $36 \%$, respectively.

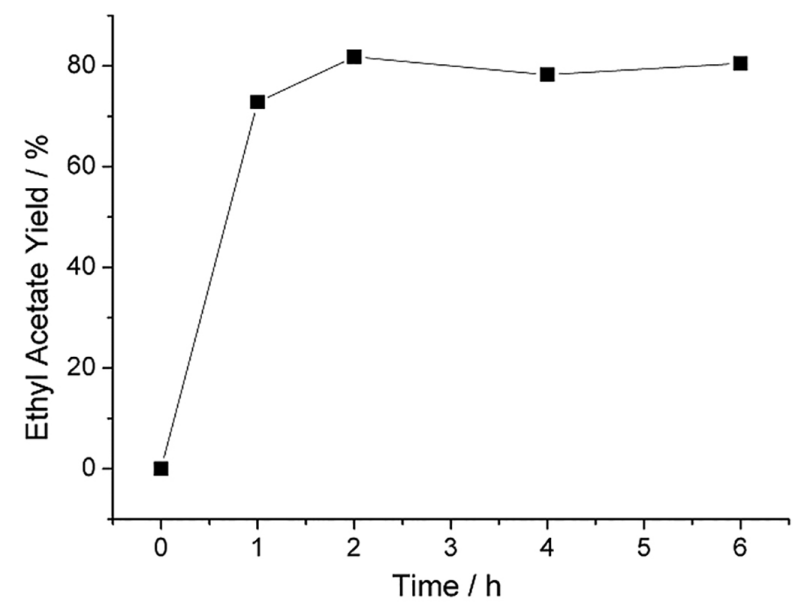

Figure 7. Yield as a function of the reaction time for the esterification of acetic acid with ethanol catalyzed by 30 wt. $\% \mathrm{H}_{3} \mathrm{PW} / \mathrm{SiO}_{2}-\mathrm{Al}_{2} \mathrm{O}_{3}$. Conditions: $100{ }^{\circ} \mathrm{C}, 2: 1$ acetic acid:ethanol molar ratio, 10 wt.\% catalyst:acetic acid mass ratio.

In order to explain the experimental activity results of the different catalysts, their acidities were quantified. Acidity is an important catalyst property and ultimately has a significant impact on the activity in the esterification reaction. Thus, the active catalysts were studied by measuring their gas-phase pyridine adsorption/desorption capacity.

Supporting $\mathrm{H}_{3} \mathrm{PW}$ on silica-alumina makes the original strong Brønsted sites of the heteropolyacids weaker, which is expected since part of the protons of $\mathrm{H}_{3} \mathrm{PW}$ reacts with silica-alumina most basic surface sites causing a leveling effect. ${ }^{9,10}$ The profiles of the desorption curves (Figure S8, in the SI section) confirmed the above statement. TPD-Py of $\mathrm{H}_{3} \mathrm{PW}$ showed a very narrow peak centered at $538^{\circ} \mathrm{C}$, which means that the acid sites are very uniform in strength (range of desorption between 300 to $600{ }^{\circ} \mathrm{C}$ ). It is interesting to note that pyridine probed practically all protons $(93 \%)$ of $\mathrm{H}_{3} \mathrm{PW}$ (Table 2). This profile is very similar to one obtained by TPD- $\mathrm{NH}_{3} .{ }^{52}$ On the other hand, the TPD-Py profiles for the supported catalysts resemble more the one obtained for silica-alumina itself, but with much less broad peaks. The curves for 15 and $20 \mathrm{wt} \%$ showed two maxima, whereas the ones for 30 and $40 \mathrm{wt} . \%$ have broad peaks with maximum about $450{ }^{\circ} \mathrm{C}$. It can be noted in all cases that most of pyridine is released up to $600{ }^{\circ} \mathrm{C}$. This is consistent with other studies involving pyridine and other amines adsorbed on silica-alumina and zeolites. ${ }^{53,54}$ Above that temperature, pyridine and other amines usually react with the solid acids forming different species as detected by TPD/MS. ${ }^{53,54}$ It is worth noting that the new distribution of acid site strengths might contribute for the good activity of the supported catalysts.

The strength distribution of the acid sites of $\mathrm{H}_{3} \mathrm{PW}$ supported material is provided in Figure 8. It can be noted that the majority of sites for 30 and $40 \mathrm{wt} \%$ supported $\mathrm{H}_{3} \mathrm{PW}$ arose between 300 and $500{ }^{\circ} \mathrm{C}$ (79 and $89 \%$ of sites, respectively), whereas the catalysts with 15 and 20 wt.\% in the same range of temperature showed 71 and $66 \%$ of sites, respectively. These data (Tables S1 and S2, in the SI section) revealed the presence of acid sites of weak to medium strengths that should be responsible for most of the measured activity. Table 2 shows the experimental versus theoretical amount of acid sites based on the total $\mathrm{H}^{+}$ presented on the surface support originating from HPA. It can be observed that the total amount of sites probed by pyridine corresponded to 97 and $91 \%$ of sites for 30 and 40 wt.\% supported $\mathrm{H}_{3} \mathrm{PW}$, respectively, whereas for 15 and $20 \mathrm{wt} . \%$, the total amount surpasses the theoretical calculation. This is because the pyridine molecule is reacting not only with the protons of $\mathrm{H}_{3} \mathrm{PW}$, but also to acidic sites on silica-alumina surface on the lower surface coverage samples. As the $\mathrm{H}_{3} \mathrm{PW}$ loading increases, the acidic surface sites of the support become less accessible because higher dispersion and coverage are reached. The maximum yield for ethyl acetate observed in Figure 4 demonstrated that $30 \mathrm{wt} \% \mathrm{H}_{3} \mathrm{PW} / \mathrm{SiO}_{2}-\mathrm{Al}_{2} \mathrm{O}_{3}$ might have the greatest accessibility for the reactants. This enhanced access to the acid sites is corroborated by the highest dispersion of this amount of $\mathrm{H}_{3} \mathrm{PW}$, according to BET specific area, i.e., a true monolayer may have been reached.

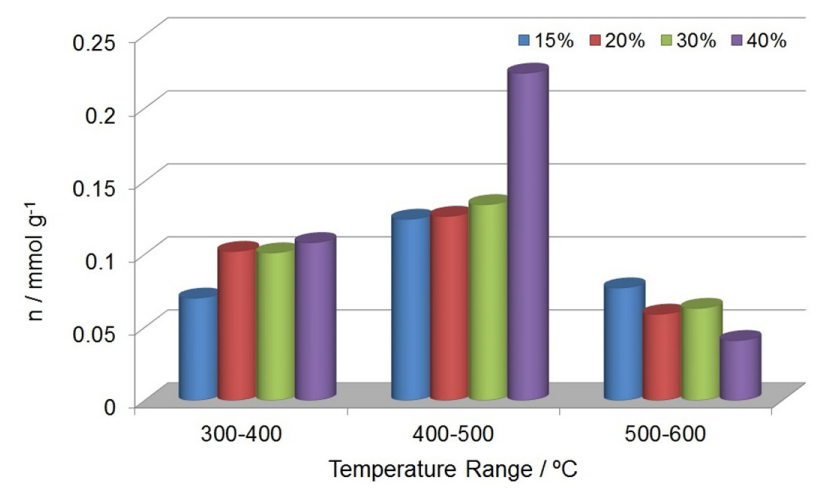

Figure 8. Distribution of the acid sites for $x$ wt. $\% \mathrm{H}_{3} \mathrm{PW} / \mathrm{SiO}_{2}-\mathrm{Al}_{2} \mathrm{O}_{3}$ determined by TG/DTG analysis of pyridine desorption between 300 and $600{ }^{\circ} \mathrm{C}$. 
The nature of the acid sites of $\mathrm{H}_{3} \mathrm{PW}$ supported on silica-alumina was also examined by FTIR (Figure 9). The pyridinium absorption bands at 1540 and $1488 \mathrm{~cm}^{-1}$ are compatible with the presence mainly of Brønsted sites, ${ }^{55}$ which are dependent on the amount of $\mathrm{H}_{3} \mathrm{PW}$ supported material (as also confirmed by TG calculations). Silica-alumina shows Brønsted and Lewis sites, depending on $\mathrm{Si} / \mathrm{Al}$ ratio, according to literature. ${ }^{38} \mathrm{We}$ have observed in our sample of protonic silica-alumina low Lewis acidity, since its characteristic absorption at $1450 \mathrm{~cm}^{-1}$ is very weak. ${ }^{55,56}$ Thus, the observed enhanced activities compared to silica-alumina are due to the occurrence of stronger Brønsted sites from $\mathrm{H}_{3} \mathrm{PW}$.

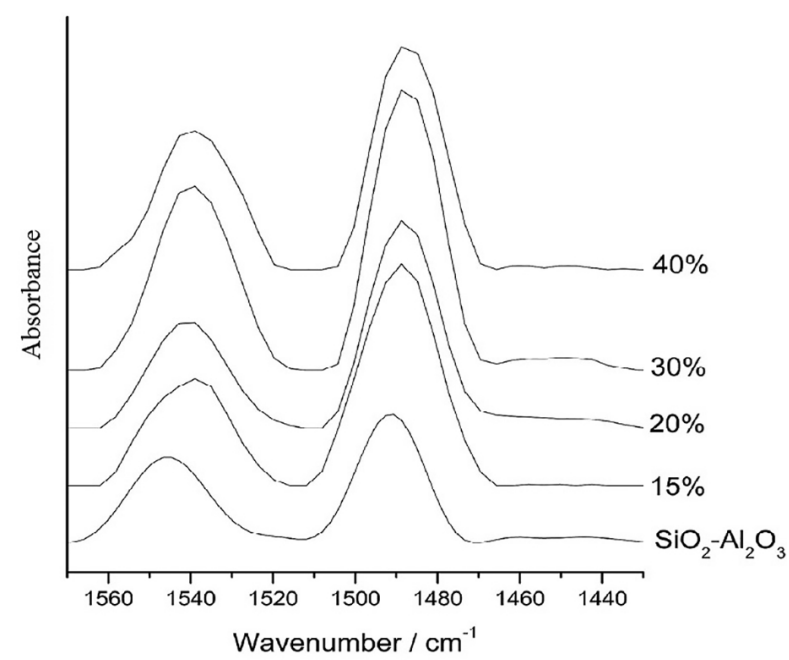

Figure 9. FTIR spectra of $x$ wt. $\% \mathrm{H}_{3} \mathrm{PW} / \mathrm{SiO}_{2}-\mathrm{Al}_{2} \mathrm{O}_{3}$ with pyridine adsorbed.

Coupling these acidity results with the activity of the catalysts in the esterification, it can be inferred that the combination of high dispersion, good interaction and adequate strength of the $30 \mathrm{wt} . \% \mathrm{H}_{3} \mathrm{PW} / \mathrm{SiO}_{2}-\mathrm{Al}_{2} \mathrm{O}_{3}$ acidic sites were probably responsible for the highest activity of this catalyst in the series. This catalyst also presented the highest turnover frequency (TOF) as calculated in Table 2. The low coverage of that catalyst (only $21 \%$ of the total specific surface of the support) associated with the strong interaction on the silica-alumina sites might be responsible for the good stability and reusability of this catalyst.

Another important issue is the leaching of $\mathrm{H}_{3} \mathrm{PW}$ supported. It is known that $\mathrm{H}_{3} \mathrm{PW}$ is very soluble in ethanol and reasonably soluble in acetic acid and ethyl acetate. ${ }^{57,58}$ Therefore, the catalyst solubility in ethanol was measured by UV-Vis because this method is very sensitive to the presence of the Keggin structure in solution. ${ }^{11,58}$ The $30 \mathrm{wt} . \%$ $\mathrm{H}_{3} \mathrm{PW} / \mathrm{SiO}_{2}-\mathrm{Al}_{2} \mathrm{O}_{3}$ catalyst was calcined at different temperatures $\left(200,300\right.$ and $\left.400{ }^{\circ} \mathrm{C}\right)$ and then added to ethanol to form a slurry. The slurry was monitored by
UV-Vis for $1 \mathrm{~h}$ (sampling solution at every $10 \mathrm{~min}$ ) to detect the Keggin anion in solution. In all the tests, the absorbance measurements were below the limit of detection, indicating that no leaching of $\mathrm{H}_{3} \mathrm{PW}$ occurred. These results suggested that the esterification reaction proceeded by heterogeneous catalysis. This behavior of $\mathrm{H}_{3} \mathrm{PW}$ supported material is in agreement with others that have detected very low leaching under adequate preparation conditions. ${ }^{59,60}$

To verify that the catalysis was truly heterogeneous, the optimized esterification reaction was repeated three times. The $30 \mathrm{wt} \% \mathrm{H}_{3} \mathrm{PW} / \mathrm{SiO}_{2}-\mathrm{Al}_{2} \mathrm{O}_{3}$ catalyst was recovered by centrifugation, washed with ethanol, dried in an oven at $100^{\circ} \mathrm{C}$ and calcined at $200^{\circ} \mathrm{C}$ before reuse. The reaction time was $2 \mathrm{~h}$, and the average yield was $79 \pm 3 \%$ (Figure 10). The yield was high and nearly constant during the recycling tests, indicating that catalyst leaching was probably very low up to three cycles. The catalyst recovery between cycles was $95 \pm 2 \%$. The recovered catalyst was subject to FTIR and XRD analyses that showed the same characteristics of the fresh sample, as described in Figures 1 and 2. Elemental analysis was conducted in this 30 wt. \% catalyst, and showed $29.6 \mathrm{wt} . \%$ (fresh) and after three recycles decreased to $29.2 \mathrm{wt} . \%$.

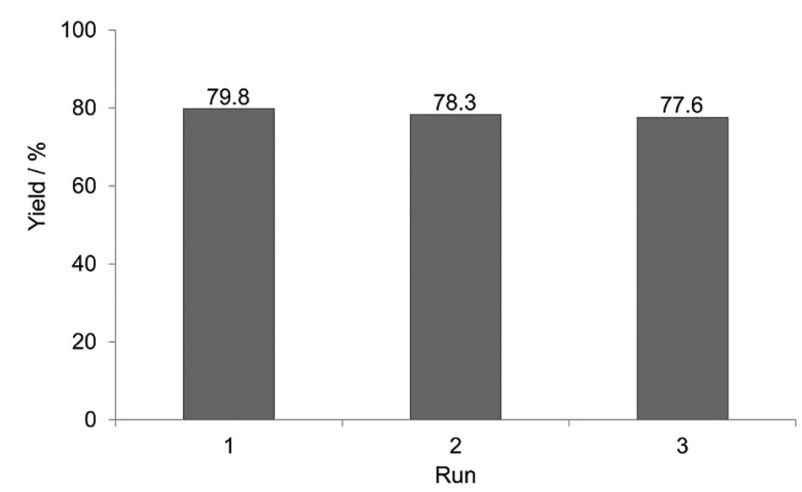

Figure 10. Catalytic runs for the esterification of acetic acid with ethanol catalyzed by $30 \mathrm{wt} . \% \mathrm{H}_{3} \mathrm{PW} / \mathrm{SiO}_{2}-\mathrm{Al}_{2} \mathrm{O}_{3}$ calcined at $300{ }^{\circ} \mathrm{C}$. Conditions: $100{ }^{\circ} \mathrm{C}$; 2 h reaction; $2: 1$ acetic acid:ethanol molar ratio; $10 \mathrm{wt} . \%$ catalyst:acetic acid mass ratio.

An additional test, which has been proposed in the literature, ${ }^{58}$ was performed to verify the level of leaching that could take place. A reaction with the $30 \mathrm{wt} . \%$ $\mathrm{H}_{3} \mathrm{PW} / \mathrm{SiO}_{2}-\mathrm{Al}_{2} \mathrm{O}_{3}$ was conducted (under the same optimized conditions) for $1 \mathrm{~h}$. The reaction was stopped, and after separation of the solid catalyst by centrifugation, it was left more $1 \mathrm{~h}$ at the same conditions (i.e., stirring at temperature of $\left.100{ }^{\circ} \mathrm{C}\right)$. The measured yield $(2 \mathrm{~h})$ was $70.1 \%$, which was about the same yield measured in the reaction after catalyst separation $(1 \mathrm{~h})$, i.e., $70.0 \%$. This demonstrates that no soluble species is responsible for any improvement in the reaction kinetics, after removing the solid acid. Also, 
the solution was tested for the presence of Keggin anions by the UV-Vis method and no detectable signal was observed. Thus, all these experimental data are in agreement with very low leaching under this method and conditions of evaluation. The leaching tests were also in agreement with ${ }^{31} \mathrm{P}$ MAS NMR results that pointed to a strong interaction of $\mathrm{H}_{3} \mathrm{PW}$ with silica-alumina surface. Coupled with the low coverage and the high accessibility degree of pyridine for the protons $(97 \%)$, it might point to that only relatively fine overlayers of nanocrystals were formed on silica-alumina surface.

\section{Conclusions}

This article presents the synthesis and characterization of a heterogeneous 12-tungstophosphoric acid $\left(\mathrm{H}_{3} \mathrm{PW}\right)$ supported on silica-alumina $\left(\mathrm{H}_{3} \mathrm{PW} / \mathrm{SiO}_{2}-\mathrm{Al}_{2} \mathrm{O}_{3}\right)$ as catalyst. It was demonstrated that impregnating the support with $\mathrm{H}_{3} \mathrm{PW}(15,20,30$ and 40 wt.\%) in an acidic solution $\left(0.1 \mathrm{~mol} \mathrm{~L}^{-1} \mathrm{HCl}\right)$ produces a catalyst with the Keggin structure as shown by FTIR and mainly ${ }^{31} \mathrm{P}$ MAS NMR. Thus, the Keggin structure can be maintained on oxide supports having aluminum, when an appropriate preparation method is used. Based on the results obtained by leaching and ${ }^{31} \mathrm{P}$ MAS NMR, it is supposed a strong interaction with the hydroxyl sites, i.e., isolated and hydrogen-bonded bridge silanols on the silica-alumina surface. From all the catalysts prepared $\left(15,20,30\right.$ and $40 \mathrm{wt} . \% \mathrm{H}_{3} \mathrm{PW}$ supported on $\mathrm{SiO}_{2}-\mathrm{Al}_{2} \mathrm{O}_{3}$ ), 30 wt. $\% \mathrm{H}_{3} \mathrm{PW} / \mathrm{SiO}_{2}-\mathrm{Al}_{2} \mathrm{O}_{3}$ was the most active for the esterification of acetic acid with ethanol. The optimized reaction conditions were: temperature of $100^{\circ} \mathrm{C}$, acetic acid:ethanol molar ratio of $2: 1$, catalyst:acetic acid mass ratio of $10 \mathrm{wt} \%$ and calcination of the catalyst at $300{ }^{\circ} \mathrm{C}$. The yield for three consecutive $2 \mathrm{~h}$ reactions was $79 \pm 3 \%$ with a selectivity of $100 \%$ (ethyl acetate) under these conditions, and the average catalyst recovery was $95 \pm 2 \%$ (obtained by centrifugation). This catalyst had a Brønsted acid site concentration of $0.299 \mathrm{mmol} \mathrm{g}^{-1}$ (mostly weak to medium), indicating that about $97 \%$ of the theoretical acid sites $\left(0.309 \mathrm{mmol} \mathrm{g}^{-1}\right)$ were accessible, based on the amount of supported $\mathrm{H}_{3} \mathrm{PW}$.

\section{Supplementary Information}

Supplementary data are available free of charge at http://jbcs.org.br as a PDF file.

\section{Acknowledgments}

We acknowledge CNPq for research, CAPES for Master, Doctorate and DPP/ProIC/CNPq for undergraduate scholarships. We also thank UnB/DPP/IQ, FINATEC,
FAPDF, MCT/CNPq, CAPES, Petrobras, FINEP/CTPetro and FINEP/CTInfra for financial support.

\section{References}

1. Long, D. L.; Burkholder, E.; Cronin, L.; Chem. Soc. Rev. 2007, 36, 105.

2. Long, D. L.; Tsunashima, R.; Cronin, L.; Angew. Chem. Int. Ed. 2010, 49, 1736.

3. Ito, T.; Polichem. 2012, 6.

4. Heravi, M. M.; Sadjadi, S.; J. Iran. Chem. Soc. 2009, 6, 1.

5. Misono, M.; Catal. Today 2009, 144, 285.

6. Kiricsi, I.; Appl. Catal., A 2003, 256, 1.

7. Hill, C. L.; Chem. Rev. 1998, 98, 1.

8. Kozhevnikov, I. V. In Catalysis by Polyoxometalates, vol. 2; Roberts, S. M., ed.; John Wiley \& Sons Ltd.: Chichester, England, 2002.

9. Dias, J. A.; Caliman, E.; Dias, S. C. L.; Paulo, M.; de Souza, A. T. C. P.; Catal. Today 2003, 85, 39.

10. Caliman, E.; Dias, J. A.; Dias, S. C. L.; Prado, A. G. S.; Catal. Today 2005, 107-108, 816.

11. Oliveira, C. F.; Dezaneti, L. M.; Garcia, F. A. C.; de Macedo, J. L.; Dias, J. A.; Dias, S. C. L.; Alvim, K. S. P.; Appl. Catal., A 2010, 372, 153.

12. Caliman, E.; Dias, J. A.; Dias, S. C. L.; Garcia, F. A. C.; de Macedo, J. L.; Almeida, L. S.; Microporous Mesoporous Mater. 2010, 132, 103.

13. Moffat, J. B.; Metal-Oxygen Clusters: The Surface and Catalytic Properties of Heteropoly Oxometalates; Kluwer: New York, USA, 2001.

14. Augustine, R. L.; Tanielyan, S. K.; Mahata, N.; Gao, Y.; Zsigmond, A.; Yang, H.; Appl. Catal., A 2003, 256, 69.

15. Ahn, S. H.; Choi, M. S.; Im, J. S.; Sheikh, R.; Park, Y. H.; J. Mol. Catal., A 2013, 373, 55.

16. Pieta, I. S.; Ishaq, M.; Wells, R. P. K.; Anderson, J. A.; Appl. Catal., A 2010, 390, 127.

17. Leydier, F.; Chizallet, C.; Chaumonnot, A.; Digne, M.; Soyer, E.; Quoineaud, A. A.; Costa, D.; Raybaud, P.; J. Catal. 2011, $284,215$.

18. Rao, K. M.; Gobetto, R.; Iannibello, A.; Zecchina, A.; J. Catal. 1989, 119, 512.

19. Pizzio, L. R.; Cáceres, C. V.; Blanco, M. N.; Appl. Catal., A 1998, 167, 283.

20. Pizzio, L. R.; Vázquez, P. G.; Cáceres, C. V.; Blanco, M. N.; Appl. Catal., A 2003, 256, 125.

21. Rao, P. M.; Wolfson, A.; Kababya, S.; Vega, S.; Landau, M. V.; J. Catal. 2005, 232, 210.

22. Romanelli, G.; Vázquez, P.; Pizzio, L.; Quaranta, N.; Autino, J.; Blanco, M.; Cáceres, C.; Appl. Catal., A 2004, 261, 163.

23. Romanelli, G.; Autino, J. C.; Vázquez, P.; Pizzio, L.; Blanco, M.; Cáceres, C.; Appl. Catal., A 2009, 352, 208. 
24. Kim, Y. T.; You, S. J.; Jung, K.-D.; Park, E. D.; Bull. Korean Chem. Soc. 2012, 33, 2369.

25. Jin, D.; Gao, J.; Hou, Z.; Guo, Y.; Lu, X.; Zhu, Y.; Zheng, X.; Appl. Catal., A 2009, 352, 259.

26. Bokade, V. V.; Yadav, G. D.; Appl. Clay Sci. 2011, 53, 263.

27. Nandhini, K. U.; Mabel, J. H.; Arabindoo, B.; Palanichamy, M.; Murugesan, V.; Microporous Mesoporous Mater. 2006, 96, 21.

28. Santos, J. S.; Dias, J. A.; Dias, S. C. L.; de Macedo, J. L.; Garcia, F. A. C.; Almeida, L. S.; de Carvalho, E. N. C. B.; Appl. Catal., A 2012, 443-444, 33.

29. Brown, G. M.; Noe-Spirlet, M. R.; Busing, W. R.; Levy, H. A.; Acta Crystallogr. Sect. B: Struct. Sci. 1977, 33, 1038.

30. Klug H. P.; Alexander, L. E.; X-ray Diffraction Procedures for Polycrystalline and Amorphous Materials; John Wiley \& Sons: New York, USA, 1962.

31. Pope, M. T.; Heteropoly and Isopoly Oxometalates; SpringerVerlag: Berlin, Germany, 1983.

32. Lefebvre, F. J.; Chem. Soc. Chem. Commun. 1992, 756.

33. Legagneux, N.; Basset, J.-M.; Thomas, A.; Lefebvre, F. J.; Goguet, A.; Sá, J.; Hardacre, C.; Dalton Trans. 2009, 2235.

34. Newman, A. D.; Brown, D. R.; Siril, P.; Lee, A. F.; Wilson, K.; Phys. Chem. Chem. Phys. 2006, 8, 2893.

35. Uchida, S.; Inumaru, K.; Misono, M.; J. Phys. Chem. B 2000, 104, 8108 .

36. Nielsen, B. P.; Onuferko, J. H.; Gates, B. C.; Ind. Eng. Chem. Fundam. 1986, 25, 337.

37. Crépeau, G.; Montouillout, V.; Vimont, A.; Mariey, L.; Cseri, T.; Maugé, F.; J. Phys. Chem. B 2006, 110, 15172.

38. Zaki, M. I.; Hasan, M. A.; Al-Sagheer, F. A.; Pasupulety, L.; Colloids Surf., A 2001, 190, 261.

39. Braga, V. S.; Dias, J. A.; Dias, S. C. L.; de Macedo, J. L.; Chem. Mater. 2005, 17, 690.

40. Dias, J. A.; Rangel, M. C.; Dias, S. C. L.; Caliman, E.; Garcia, F. A. C.; Appl. Catal., A 2007, 328, 189.

41. Gregg, S. J.; Sing, K. S. W.; Adsorption, Surface Area and Porosity, $2^{\text {nd }}$ ed.; Academic Press Inc.: London, Great Britain, 1982.
42. Braga, P. R. S.; Costa, A. A.; de Freitas, E. F.; Rocha, R. O.; de Macedo, J. L.; Araujo, A. S.; Dias, J. A.; Dias, S. C. L.; J. Mol. Catal. A: Chem. 2012, 358, 99.

43. Webb, P. A.; Orr, C.; Analytical Methods in Fine Particle Technology; Micromeritics Instrument Corporation: Norcross, USA, 1997.

44. Sakamuri, R. In Encyclopedia of Chemical Technology; Othmer, K., ed.; John Wiley \& Sons: London, England, 2003.

45. Bhorodwaj, S. K.; Pathak, M. G.; Dutta, D. K.; Catal. Lett. 2009, 133, 185.

46. Pereira, C. S. M.; Pinho, S. P.; Silva, V. M. T. M.; Rodrigues, A. E.; Ind. Eng. Chem. Res. 2008, 47, 1453.

47. Das, J.; Parida, K. M.; J. Mol. Catal. A: Chem. 2007, 264, 248.

48. Chakraborty, A. K.; Basak, A.; Grover, V.; J. Org. Chem. 1999, 64, 8014.

49. Leilei, X.; Yihang, G.; Huiru, M.; Jianguo, G.; J. Wuhan Univ. Technol. Mater. Sci. Ed. 2013, 28, 580.

50. Gurav, H.; Bokade, V. V.; J. Nat. Gas Chem. 2010, 19, 161.

51. López, D. E.; Suwannak, K.; Goodwin Jr., J. G.; Bruce, D. A.; Ind. Eng. Chem. Res. 2008, 47, 2221.

52. Okuhara, T.; Mizuno, N.; Misono, M.; Adv. Catal. 1996, 41, 113.

53. Parrilo, D. J.; Adamo, A. T.; Kokotailo, G. T.; Gorte, R. J.; Appl. Catal. 1990, 67, 107.

54. Tittensor, J. G.; Gorte, R. J.; Chapman, D. M.; J. Catal. 1992, 138, 714.

55. Parry, E. P.; J. Catal. 1963, 2, 371.

56. Topsoe, N.-Y.; Pedersen, K.; Derouane, E. G.; J. Catal. 1981, $70,41$.

57. Izume, Y.; Hasebe, R.; Urabe, K.; J. Catal. 1983, 84, 402.

58. Alsalme, A.; Kozhevnikova, E. F.; Kozhevnikov, I. V.; Appl. Catal., A 2008, 349, 170.

59. Scroccaro, K. I.; Tanobe, V. O. A.; Côcco, L. C.; Yamamoto, C. I.; Wypych, F.; Quim. Nova 2012, 35, 1343.

60. Sepúlveda, J. H.; Vera, C. R.; Yori, J. C.; Badano, J. M.; Santarosa, D.; Mandelli, D.; Quim. Nova 2011, 34, 601.

Submitted: March 3, 2016

Published: June 14, 2016 